\title{
The Auteur and the 80s Mixtape
}

Popular Music and Authenticity in Metal Gear Solid V: The

Phantom Pain

ANDRA IVĂNESCU

\section{Abstract}

The specters of music past can play a multitude of roles in videogames set in versions of a historical past. This chapter looks at the use of appropriated pre-existing popular music in Metal Gear Solid V: The Phantom Pain (2015), as a mixtape that embodies multiple forms of authenticity. Drawing of theories surrounding nostalgia, realism, auteurship, and authenticity itself, the chapter explores the 1980s in-game collectable cassette tapes. These are examined in relation to the game's narrative and its complex views on history and war; its auteur - Hideo Kojima - whose own mythology is intertwined with the mythology of the series; and the relationship between the two in a changing industrial and socio-political landscape.

\section{The Man Who Sold the World}

One of the earliest images on which the camera lingers in Metal Gear Solid V: The Phantom Pain (2015) is a cassette tape. It is not a weapon, nor a soldier, although the sounds of war fill the player's ears as soon as the game is started. It is not the infamous cardboard box under which various iterations of Snake or other protagonists have comically hidden. It is a cassette tape on which 'From the Man Who Sold the World' can be seen in green lettering. The camera zooms in on it, ignoring the bullets and the pills strewn around; during a fade, a click is heard, and then the cassette comes back into focus; the Sony tape is placed into the Sony Walkman and the camera zooms in, focusing on the tape moving, the white noise of tape rolling before there is sound. Another fade, and then the song plays. The game has begun.

The Phantom Pain is an open-world military stealth game that follows the journey of Punished 'Venom' Snake and his paramilitary organization through Afghanistan and the Angola-Zaire border region, in many respects following the 
tradition of the Metal Gear (and particularly Metal Gear Solid) games in terms of its innovative mechanics, its combination of military realism and outlandish fantasy, and its thematic interest in identity, war, and nuclear deterrence.

The song that begins the game - Midge Ure's version of the well-known David Bowie track (first released in 1970) - is one of a number of 1980s pop songs present throughout The Phantom Pain, the only game in the Metal Gear series to feature licensed pre-existing pop music. These songs that can be found in cassette players throughout the game act as multi-layered signifiers, emphasizing the game's 1984 setting (not always accurately but authentically), foreshadowing elements of the game's plot, and playing on virtual and real histories and futures in often convoluted ways. This chapter examines these para-musical connotations in relation to the concept of authenticity, but also ideas regarding hauntology, reflective nostalgia, and auteur theory, ultimately looking at how these meanings are intertwined with the game's own complex temporality, constructing a semiotic web in which Kojima is positioned as both medium and prophet.

\section{The Auteur}

Elsewhere, I define nostalgia videogames as "videogames which appropriate not only the aesthetics and generic universes of media of the past, but their signifying systems, often with the potential of accessing social, political, and cultural themes through the lens (or magnifying glass) of popular culture past." Throughout nostalgia videogames, the specters of music past contribute to the construction of soundscapes that tell us as much about history as they do about the social and political contexts of their production, as well as the imagined futures they contain. ${ }^{2}$ This is exemplified in many critically acclaimed videogames of the 21st century, from Grand Theft Auto: Vice City (2002) to BioShock (2007), and their sequels. Metal Gear Solid V: The Phantom PAIN, however, adds another dimension to the receptions and interpretation of its pre-existing music, scattered throughout the gameworld in the form of collectable cassette tapes that its protagonist Punished 'Venom' Snake can pick up. This dimension is that of its auteur - Hideo Kojima - whose own mythology is intertwined with the mythology of the series.

As deWinter notes, Kojima is often deemed "the first video game auteur". 3 His personality has dominated the perception of the Metal Gear series (since

\footnotetext{
${ }^{1}$ Ivănescu, Andra: Appropriated Music in the Nostalgia Video Game: The Way It Never Sounded, London: Palgrave Macmillan 2019, p. 26.

${ }^{2}$ Cf. A. Ivănescu: Appropriated Music in the Nostalgia Video Game.

3 deWinter, Jennifer: "Miyamoto/Kojima: Authorship", In Matthew Thomas Payne/Nina B. Huntemann (eds.), How to Play Videogames. New York, NY: New York University Press 2019, p. 183.
} 
1987) and it is evident why it continues to fascinate after and outside of the franchise. Drawing on classic auteur theory, Kojima certainly fits the mould, ticking all of the boxes in Andrew Sarris's traditional definition of the auteur through his technical skills and role in the development of the stealth genre, his over-the-top cinematic style (and occasionally excessive cut-scenes), and the at times convoluted inner meaning of his games, the topic of numerous websites, forums, and Reddit threads. ${ }^{4}$ The formal and aesthetic characteristics of his oeuvre are, however, only part of what constructs Kojima's auteurship. Indeed, as Corrigan argues, "auteurs, and theories and practices of auteurism have never been a consistent or stable way of talking about movies" and this remains true of videogame auteurs. ${ }^{5}$

Corrigan links the rise of auteur theory to "changes in industrial desires, technological opportunities, and marketing strategies." "Its adoption in relation to videogames certainly mirrored similar changes, as Kojima's career evolved alongside the growth of the industry. deWinter, in the first monograph of the Bloomsbury Influential Game Designer series, highlights the fact that "during the initial rise of video gaming, most players would have been hard-pressed to name a game designer." ${ }^{, 7}$ In other words, the celebration of Kojima as auteur may be problematic, as auteurism has always been (even more so in relation to videogames), but it also reflects changes in perception, legitimacy, and marketing, related to industrial, journalistic, and community practices.

Moreover, Kojima does not simply approve of this image, but encourages his own celebrity in a pursuit of self-mythologizing brand construction. An example of this is the way in which his presence is increasingly pervasive throughout his work. While his name appears in numerous positions in the credits of his games - writer, director, creative director - his voice and literal image are now part of them too. From playing the literal voice of God in Metal Gear Solid 4 (2008), Kojima could only go one step further - placing himself as a character in his own game. Appearing first in Metal Gear Solid V: Ground Zeroes (2014), Hideo can be rescued as part of the side op 'Intel Operative Rescue' and can then be retained as Mother Base staff for the entirety of Metal Gear Solid V, including The Phantom Pain, which links directly to the events of Ground Zeroes. The extended Easter egg delivers nods not only to the beginnings of the recognition of authorship in games, such as the first ever Easter egg by Warren

\footnotetext{
${ }^{4}$ Sarris, Andrew: "Notes on Auteur Theory in 1962", In Leo Braudy/Marshall (eds.) Film Theory and Criticism, Oxford: Oxford University Press, pp. 562-563.

${ }^{5}$ Corrigan, Timothy: "Auteurs and the New Hollywood", In Jon Lewis (ed). The New American Cinema, Durham, NC: Duke University Press 1998, p. 40.

${ }^{6}$ Ibid.

${ }^{7}$ deWinter, Jennifer: Shigeru Miyamoto: Super Mario Bros., Donkey Kong, The Legend of Zelda. New York: Bloomsbury 2015, p. x.
} 
Robinett, ${ }^{8}$ but also to auteurs like Alfred Hitchcock and Quentin Tarantino, who famously appear in their own films in either cameos or fully-fledged roles.

In terms of The Phantom PAIN, the role of the auteur is further emphasized by the troubled development of the game, which marked the split between Kojima and his long-standing employer Konami. Corrigan argues that "[Orson] Welles connected to [Francis Ford] Coppola across the heyday of auteurism as Romantic expression and independent (if not transgressive) vision." 9 The line certainly does not stop with Coppola, but continues all the way to Kojima, who fosters a strikingly similar "ambivalent double image as the auteur-star of gigantic productions and the auteur-creator victimized by the forces of those productions." 10 The highly publicized split marks Kojima as an authentic creator, and leaves The Phantom Pain marked by unfulfilled potential.

Ultimately, The Phantom PAIn is inseparable from the image of its creator, or from the history of its own production, and this is why its songs have been interpreted as a clear message, as unmitigated communication from Kojima to Konami, as a breakup mixtape. ${ }^{11}$

\section{The Mixtape}

Alongside 'The Man Who Sold the World', which plays at the beginning of the game, there are 16 cassette tapes featuring pre-existing pop music that can be collected throughout the open world of The Phantom Pain, totalling 17 pop songs that can be heard in the game. This collection of songs can be largely understood from three different perspectives: in terms of their collection as part of the gameplay, of the music itself, and of their materiality as cassettes and their relationship to the Walkman as technology that bridges and blurs relationships between the private and the public. ${ }^{12}$ While these three aspects will initially be considered separately here, they are certainly inter-related, and, indeed, inexorably linked.

\section{The Game}

\footnotetext{
${ }^{8}$ Game designer Warren Robinett is well-known for including a hidden screen in Atari's 1979 game Adventure which stated "Created by Warren Robinett", widely considered to be the first Easter egg in a videogame.

${ }^{9}$ T. Corrigan: "Auteurs and the New Hollywood", p. 52.

${ }^{10}$ Ibid., p. 54.

${ }^{11}$ Keerssemeeckers, Stefan: "MGS 5's Soundtrack is All About the Kojima/Konami Split", in Kotaku, March 17, 2017, https://www.kotaku.co.uk/2017/03/17/mgs5s-soundtrack-is-all-about-the-kojima-konami-s plit

${ }^{12}$ Cf. Du Gay, Paul/ Hall, Stuart/ Janes, Linda/ Mackay, Hugh/ Negus, Keith: Doing Cultural Studies: The Story of the Sony Walkman, London: Sage Publications (in association with the Open University) [1997] 2013.
} 
The cassettes featuring pre-existing pop music form only a small part of the cassettes in The Phantom Pain, which can be divided into three broad categories: Intel, Music, and Acquired Tapes ${ }^{13}$. To the aversion of many die-hard Metal Gear fans, a significant amount of the plot of Metal Gear Solid V is not revealed through Kojima's typical extended cut-scenes, but through the Intel tapes, which expand on details of individual missions, characters, and histories. These tapes are generally delivered to the player at the end of missions. The Acquired tapes can be found in the field, and they play diegetic sounds with transdiegetic effects. Playing them will have a one-time effect, benefiting the player in ways that reflect the nature of the sounds on the tape (for instance, the sounds of an animal will make that type of animal less likely to run from the player-character). The Music Tapes are divided into two categories: Music Tape 1 features primarily instrumental tracks from the current game's soundtrack and from past Metal Gear Solid games (like the Peace Walker [2010] theme 'Heavens Divide') with one exception - Richard Wagner's 'Ride of the Valkyries' - the only piece with a named composer or artist in the entire list of cassettes. Music Tape 2 features collectible cassettes of pre-existing pop music (see Figure 1 for a full list) which can be found throughout the two primary locations of the game - Afghanistan and the Angola-Zaire border region.

Figure 1. The 16 tracks on Music Tape 2, in the order in which they appear in the playlist.

\begin{tabular}{|l|c|}
\hline Artist & Song Title \\
\hline Laura Branigan & Gloria \\
\hline Kim Wilde & Kids in America \\
\hline Billy Idol & Rebel Yell - 1999 Digital Remaster \\
\hline Europe & The Final Countdown \\
\hline a-ha & Take on Me \\
\hline Hall \& Oates & Maneater \\
\hline Asia & Only Time Will Tell \\
\hline Joy Division & Love Will Tear Us Apart \\
\hline Spandau Ballet & True \\
\hline
\end{tabular}

\footnotetext{
${ }^{13}$ These appear as separate categories (and tabs) under the Cassette Tapes Menu.
} 


\begin{tabular}{|l|c|}
\hline The Cure & Friday I'm in Love \\
\hline Ultravox & Dancing with Tears in My Eyes \\
\hline Dead or Alive & You Spin Me Round (Like a Record) \\
\hline Japan & Quiet Life \\
\hline Thomas Dolby & She Blinded Me with Science \\
\hline Kajagoogoo & Too Shy \\
\hline
\end{tabular}

As the only example of appropriated music outside of Music Tape 2, 'Ride of the Valkyries' deserves particular attention. ${ }^{14}$ The intertextual reference to the iconic scene in the film ApOcAlypse Now (2001) is emblematic of Kojima's cinematic style and influences (and draws further connections between him and auteur Francis Ford Coppola), but is also important in how it changes the experience for the player, for whom this explicit reference reframes the scenes themselves as more grounded in cinematic representation than in anthentic past, especially when the helicopter is a primary mode of transport in the game, offering many parallels to the famous scene in the film. At the same time, this in itself reflects the experience of actual soldiers. Daughtry problematizes "the importance of film as a mediator of service members' lived experience of combat", directly referencing 'Ride of the Valkyries' as a common presence on "battle playlists". ${ }^{15}$ In making their violent video game experience more cinematic, players' experiences mirror those of real-life soldiers, authenticity (the unmediated real) and simulacra (the mediated without a real) one and the same, as they are more often than not.

Music Tape 2, however, plays a different role here. Unlike 'Ride of the Valkyries', and with the exception of the song featured in the introduction - 'The Man Who sold the World'- the songs on the tape need to be found and collected by players from enemy locations. The tapes can be located through listening, as the songs can be heard playing from enemy cassette players at a short distance while accomplishing missions. Gibbons, drawing on Michel Chion, describes this as acousmatic sound, which "can be aurally located in an unseen, offscreen space (e.g., in the next room, upstairs, behind a screen)" and "asks viewers or

\footnotetext{
${ }^{14}$ While The Phantom Pain is the main focus here, it should also be noted that previous games in the series also include 'Ride of the Valkyries', including the prologue Ground ZEROES.

${ }^{15}$ Daughtry, J. Martin: "Aural Armor: Charting the militarization of the iPod in operation Iraqi freedom", In Sumanth Gopinath/ Jason Stanyek, (eds.). The Oxford Handbook of Mobile Music Studies, Volume 1, Oxford: Oxford University Press 2014, p. 234.
} 
players a question, beckoning them." ${ }^{, 16}$ In a typical scenario, a player would hear a song - the sound muffled and tinny - and follow it inside a room, press the cassette player and take the cassette, which would stop playing, but appear in the Music Tape 2 playlist on the player's 'iDroid', from where it can be played at any point afterwards.

The way in which the cassettes function in relation to gameplay is both similar and distinct from uses of appropriated music in similar games. On the one hand, the diegetic nature of the cassettes, and the focus on the materiality of appropriated sound, the overtly diegetic hypermediacy, are all typical of appropriated music in nostalgia games. ${ }^{17}$ From the radios of the GRAND THEFT Auto series (since 1997) to the cassettes of Gone Home (2013), musical technologies are emphasized alongside the appropriated music they play in games, often lovingly. Players of The Phantom Pain, however, have more agency over these songs than generally afforded - not only is the ability to play them linked to player action (if a song is not found, it cannot be played), but picking and playing individual songs is rare, as is having a fixed order in which they can be played.$^{18}$ Furthermore, there are some particularities to the playlist in The Phantom Pain that distinguish it from other playlists from nostalgia games, if the game can be described as a nostalgia game at all.

\section{The Music}

The Phantom Pain is not a straightforward nostalgia game, in that its systems of reference, and its generic universe, while clearly grounded in the 1980s historically (as much of its Intel tapes attest) and in terms of cinematic influence (as its blockbuster aesthetic demonstrates), are not significantly different from the other games in the series. In other words, the aesthetics of the games in the series are consistent, and appear to be unrelated to the generic universes specific to their various settings, unlike, say, the differences between Grand THEFT Auto: Vice City and Grand Theft Auto: San Andreas (2004), whereby their aesthetics are grounded in different, decade- and place-specific areas of influence. It is, furthermore, also apparent that the game is not actually nostalgic, in that its vision of the past is one that vehemently resists any desire to return, any longing for what once was. There is no desire for the 'homecoming' implied in the etymology of 'nostalgia'; if anything, the discussed issues of war hit a bit

\footnotetext{
${ }^{16}$ Gibbons, William: "Wrap Your Troubles in Dreams: Popular Music, Narrative, and Dystopia in BioShock", in: Game Studies 11 (2011). Available at: http://gamestudies.org/1103/articles/gibbons

${ }_{17}^{17}$ A. Ivănescu: Appropriated Music in the Nostalgia Video Game.

${ }^{18}$ Gone Home is mechanically similar, in that tapes can be collected and played by the player themselves. The Riot Grrrl tapes of Gone Home, however, play different aesthetic functions, as evidenced by both their generic consistency, and the fact that they are presented more like individual artefacts than the ones in THe РнаNтом Pain.
} 
too close to 'home' already. Nevertheless, The Phantom Pain does poignantly focus on details of its time and its themes and plot, however sci-fi they become, are grounded in political and cultural ideas that are as poignant as those of nostalgia games. The game thus finds itself in a unique place, where its systems of reference and its nostalgic setting generally overlap but can also be independent from each other. Its use of appropriated music reflects this ambivalence.

Like in all nostalgia games, the appropriated music on Music Tape 2 plays a clear function here as a temporal signifier. Indeed, most of the songs on the playlist were recorded between 1980 and 1984 (the game's setting), the playlist even featuring 1980s cover versions of previously recorded songs, like Laura Branigan's 'Gloria' (originally recorded by Umberto Tozzi in 1979) and, more notably, Midge Ure's version of David Bowie's 1970 classic 'The Man Who Sold the World'. There are, however, three exceptions to this: Dead or Alive's 'You Spin Me Round (Like a Record)' (released in 1985), Europe's 'The Final Countdown' (released in 1986), and, most stridently perhaps, The Cure's 1992 single 'Friday I'm in Love'. At the same time, it is evident that these choices, while not accurate within the setting of the game, act as signifiers for a broader idea of the 1980s, as is exemplified by The Cure - although the songs itself is from the early 1990s, The Cure are more well-known for their role in the 1980s Goth scene, and would thus not feel out of place in an 1980s playlist to most listeners. In other words, its actual accuracy is less important than its authenticity function. Authenticity is not really related to historical accuracy, but to accurate communication, as semiotic shorthand.

The playlist's length and breadth also distinguish it from other nostalgia games. It is not an extensive playlist defining the genres of a particular decade, like those of the GRAND TheFt Auto series, nor does it have the subcultural capital of Gone Home's 'Riot Grrrl' music. Its Top 40 ethos and 16 track-length make it more akin to a very specific type of playlist - the mixtape. While the songs are collected on individual cassette tapes, they are then compiled into a unified - albeit unassumingly titled - playlist, one that is both personal and meant to be shared. As Rando argues, "the mixtape comes into being through a wishful act of compiling and sharing of music; whatever the particular purpose or context that gives rise to the individual mixtape, its basic drive is always to assemble music into new configurations and to share it with others." ${ }^{\prime \prime}$ In this case, the configuration tells a story that goes beyond the individual songs, and beyond the game itself. As Stefan Keerssemeeckers outlines in a meticulous article for the videogame website Kotaku, "MGS 5's Soundtrack is All About the Kojima/Konami Split". ${ }^{20}$

19 Rando, David: Hope and Wish Image in Music Technology. London: Palgrave Macmillan 2017, pp. 64-65.

${ }^{20}$ S. Keerssemeeckers, Stefan: "MGS 5's Soundtrack is All About the Kojima/Konami Split”, 2017. 
Keerssemeeckers does not just unpack how the lyrical content of some of the included songs reflect potential aspects of the 'breakup' - "Maneater might very well be Kojima telling us Konami is acting like a measly bean counter, or even suggesting that they exist only to chew up and spit out their employees" 21 - but also examines what Philip Tagg describes as the "para-musical fields of connotation" (PMFCs) of the music, which he argues "exist along-side or in connection with the music, as an intrinsic part of musical semiosis in a real cultural context, not as external appendages to the music." 22 The PMFCs discussed in the Keerssemeeckers article include earlier recordings of the songs ('Gloria' and 'Man Who Sold the World') and the struggles of frontmen like Kajagoogoo's Limahl and The Cure's Robert Smith. Like Rando notes, "the mixtape does not obscure the way its individual tracks functioned in their original contexts, nor does it long to return to those lost contexts; instead, it brings the disparate tracks into relationship with one another.",23

This reading of the mixtape is one that sees it as personal to Hideo Kojima, and that would not be possible without his auteur status, and his close association with the franchise since its inception, only exacerbated after its critical and commercial failure after Kojima's departure. The music included is thus seen as what DeNora calls a "technology of the self", whereby "music is a cultural resource that actors may mobilize for their on-going work of self-construction and the emotional, memory and biographical work such a project entails." 24 Indeed, there are clear affinities between the Kojima/Konami breakup mixtape and the emotional work analyzed by DeNora, particularly what she describes as "venting", like a teenager playing anti-establishment music loudly in their room as both working through their emotions (as private work) and sending a message to their parents (as public communication).

At the same time, the game's 1980s setting, the cassettes collected, and the focus on the Walkman as technology, also situate the mixtape as part of a "technostalgic impulse," whereby "the use of the past" is a way to "make sense of the present." 25 Rando also acknowledges the importance of technology in relation to the mixtape more broadly, arguing that "homemade mixtapes combine personal and collective impulses with technology, beginning with cassette technology."26

\section{The Walkman}

\footnotetext{
${ }^{21}$ Ibid.

${ }^{22}$ Tagg, Philip: Music's Meanings: A Modern Musicology for Non-Musos. New York \& Huddersfield: The Mass Media Music Scholars' Press 2012, p. 229.

${ }^{23}$ D. Rando, David: Hope and Wish Image in Music Technology, p. 85.

${ }^{24}$ DeNora, Tia: "Music as technology of the self", in: Poetics 27 (1999), p. 32.

${ }^{25}$ Eley, Craig: "Technostalgia and the Resurgence of Cassette Culture", In Joseph P. Fisher/ Brian Flota (eds.) The Politics of Post-9/11 Music: Sound, Trauma, and the Music Industry in the Time of Terror, London: Ashgate 2011, pp. 51.

${ }^{26}$ D. Rando, David: Hope and Wish Image in Music Technology, p. 68.
} 
Nostalgia games often focus on the materiality of sound and of song through explicit placement in the diegesis, and through aural clues (a record crackle, a fraction of white noise before a tape starts, etc.). This not only emphasizes the mediated status of the sound, but it also indicates the appropriated status of said music. ${ }^{27}$ In The Phantom Pain, however, the material reference is more specific - this is not music listened to on any tape player, this is a Sony Walkman, with all the significance that the object and the brand bring with them.

In a seminal 1997 work of cultural studies by du Gay et al, the Sony Walkman becomes the central object, the central text, to be analysed. ${ }^{28}$ As they note: "For a time the Walkman seemed to be everywhere. Being without one was being out of the loop. Not knowing about it was being from another planet." ${ }^{\prime 29}$ The changes that the Sony Walkman brought about with its release in 1979 and its subsequent popularity cannot be underestimated. William Gibson declared that "the Sony Walkman has done more to change human perception than any virtual reality gadget." ${ }^{\prime 0}$ Drawing on Iain Chambers's work, du Gay et al discuss it as a technology that bridged and even "disturbed" relationships between the private and the public by engaging in a "private act" (listening) in "public spaces" ${ }^{31}$ but also by being an object that is "designed to be worn [publicly], like one's clothes, as part of one's self-image or self-styling." ${ }^{\prime 32}$ The Walkman itself thus mirrors the mixtape in its dual private/public function.

The discourse surrounding the Walkman cannot, however, be separated from its production. As du Gay et al unpack the history and mythology of its inception, production, and popularity, it becomes clear that that the Walkman is a product and a symbol that is Japanese, but also global. They eloquently note that "the Walkman is the product of Japanese technology and management, its appearance is as a global product - and the language of global consumerism is, of course, English (or, actually, American), ${ }^{, 33}$ and remain essential to its perception. It is, of course, important to note that the Metal Gear franchise is also emblematically Japanese, although its characters and stories, as well as its popularity, are global, and speak "the language of consumerism" (itself quite literally critiqued within the game) in more ways than one. Furthermore, while The Phantom Pain is not a PlayStation exclusive, it can, like many of its predecessors (or rather all, retroactively) be played on Sony's flagship console.

\footnotetext{
${ }^{27}$ A. Ivănescu: Appropriated Music in the Nostalgia Video Game, p. 37.

${ }^{28}$ P. Du Gay/S. Hall/L. Janes/ H. Mackay/K. Negus: Doing Cultural Studies: The Story of the Sony Walkman.

${ }^{29}$ Ibid. p. xi

${ }^{30}$ Quoted in Bull, Michael: Sounding out the City. Personal Stereos and the Management of Everyday Life. Oxford: Berg 2000, p. 1

${ }^{31}$ P. Du Gay/S. Hall/L. Janes/ H. Mackay/K. Negus: Doing Cultural Studies: The Story of the Sony Walkman, p. 106.

${ }^{32}$ Ibid., p. 18.

${ }^{33}$ Ibid., p. 22.
} 
The Walkman, the PlayStation, and Metal Gear are all emblematic of broader commercial and cultural ley lines. The personal stereo is significant in building many of these; it is private and public, Japanese and global, speaking the lingua franca of capitalism and culture.

More than bridging space, Bull argues that the Walkman reconfigures it, or rather users' experience of it, which is often described in "solipsistic and aesthetic terms", whereby it provides "an invisible shell for the user within which the boundaries of both cognitive and physical space become reformulated." 34 The experience of players can mirror that of Walkman users directly. Playing the music while wandering through the spaces of the game, whether infiltrating outposts, saving animals, or fulfilling missions, the music reframes the experience, and grounds it, providing "a unique connection to a real (or perhaps hyperreal) past, through which the historical grounding of these myths and the underlying social and cultural issues behind them, are invoked." ${ }^{35}$

\section{THE HISTORY}

The Phantom Pain is set in 1984, nine years after its prolog Ground Zeroes, and only three years before the release of the first Metal Gear game in 1987. This particular moment appears significant in completing the METAL GEAR lore its ending in a way completes the series' own history, as well as the part of Kojima's career that is linked to Konami, the company he joined in 1986 . The temporal setting is indicative of many of the game's complexities, and multi-layered signifiers - it reflects on a real historical period, grounded in representations of real geographies and conflicts, but also its own history and mythology, on top of which layers of the speculative and often times the absurd can both distract from and draw attention to its serious themes. As Green notes, “it is perhaps through the games' balancing of historicity and ahistoricity and their embracing of the bizarre - elements like the appearance of the Man on Fire and the Floating Boy - that serve to anchor the narrative in a conversation about violence, trauma, and PTSD." 36 THE PHANTOM PAIN's relationship to history is multifaceted, but one aspect of this relationship is clear: this is not meant to be a representation of history, but a reflection on it.

Both Green and Girina discuss the game's treatment of history in relation to post-9/11 global politics and conflict. ${ }^{37}$ On the one hand, the game explicitly

\footnotetext{
${ }^{34}$ M. Bull: Sounding out the City. Personal Stereos and the Management of Everyday Life, p. 31.

${ }^{35}$ A. Ivănescu: Appropriated Music in the Nostalgia Video Game, p. 194.

${ }^{36}$ Green, Amy: Posttraumatic Stress Disorder, Trauma, and History in Metal Gear Solid V. London: Palgrave Macmillan 2017, p. 24.

${ }^{37}$ Ibid. and Girina, Ivan: "Needs to Be Done": The Representation of Torture in Video Games and in Metal Gear Solid V', in Berenike Jung/Stella Bruzzi (eds.) Beyond the Rhetoric of Pain. London: Routledge, pp. 137-158.
} 
discusses the global conflicts which were ongoing in 1984, including the Soviet occupation of Afghanistan and the Angolan Civil War. The player is explicitly briefed on this through a series of cassette tapes that describe "Afghanistan Today" and "Africa Today" which, albeit brief (often one or two minutes per briefing), clearly contextualise the game's events, which themselves are of course fictional. At the same time, however, the geographical settings of THE Phantom Pain, as well as its prologue Ground Zeroes (set in Cuba), represent a broader critique of long-standing conflicts in both the Middle East and "how outside presences have shaped much of that region for far longer," and regions of Africa where it explores "the plight of child soldiers and the influence of colonizers." ${ }^{\prime 3}$ The historical setting is thus a means to discuss current global politics and put forward the game's (and the series') broader thesis about war and its victims. Parallels are to be drawn here once again between The Phantom PAIN and nostalgia games, in that their grounding in the past only emphasises issues that have never been more current. As Svetlana Boym argues, through nostalgic reconstruction, "the past is remade in the image of the present or a desired future." ${ }^{\prime 9}$ However, as argued before, the reconstruction in the game, albeit grounded in the past, from the historical position of the present, is hardly a nostalgic one, its pessimism acting more as a warning than a hope. Thus, Jacques Derrida's concept of hauntology would be more appropriate here, in a dual sense, whereby the specters of the present haunt the setting of the game as much as the historical settings of the game haunt the player's present. ${ }^{40}$ These are, as hauntology describes, both present and absent in the act of play, and act once again on a number of levels, with THE PHANTOM PAIN as both prequel and sequel to most of the games in the series, its own temporality out of joint.

In terms of its relationship to history, the setting of The Phantom Pain may also be described as a form of what Salvati and Bullinger describe as "selective authenticity" "which, may be understood as a form of narrative license, in which an interactive experience of the past blends historical representation with generic conventions and audience expectations." ${ }^{\prime 1}$ The PhAntom PAIN, however, is different from the games discussed by Salvati and Bullinger in that its plot is not closely intertwined with historical events, but uses the historical setting as part of a hauntological state wherein it is both present and absent, both past and present. Furthermore, while Salvati and Bullinger's analysis certainly engages with the complexities and potentialities of the representation of history, their concept of

\footnotetext{
38 A. Green: Posttraumatic Stress Disorder, Trauma, and History in Metal Gear Solid V, p. 24.

${ }^{39}$ Boym, Svetlana: The Future of Nostalgia. New York, NY: Basic Books 2001, p. 354.

${ }^{40}$ Derrida, Jacques: Spectres of Marx, tr. Peggy Kamuf. Routledge: New York and London ([1993] 2006).

${ }^{41}$ Salvati, Andrew/Bullinger, Jonathan M.: "Selective Authenticity and the Playable Past", In Matthew Wilhelm Kapell and Andrew B. R. Elliott (eds) Playing with the Past: Digital Games and the Simulation of History. New York, NY: Blooms-bury, pp. 153.
} 
"selective authenticity" does not entirely acknowledge the connotations of 'authenticity' as a term. In their work, the term, while clearly chosen for its implication, is used nearly interchangeably with terms like 'fidelity' and 'accuracy'. However, discussions surrounding authenticity in popular culture, and particularly popular music, complicate this relationship beyond ideas of accuracy, and situate it within larger discourses which are integral to all of the topics discussed in this chapter, including militarism and realism, mixtapes and popular music, and auteur theory.

\section{Authenticity}

All of the ideas present here so far relate, in one form or another, to the concept of authenticity, and how it is conveyed in and upon The Phantom Pain. Three layers of authenticity emerge, which loosely correspond to the three layers that Taylor and Barker describe in the quest for authenticity in popular music: representational authenticity, cultural authenticity, and personal authenticity, all of which are foregrounded in the act of play. ${ }^{42}$

\section{Representational Authenticity}

For Taylor and Barker, representational authenticity is "music that is exactly what it says it is - unlike, say, Milli Vanilli posing as singers, which they weren't." ${ }^{43}$ In other words, representational authenticity is about the relationship between that which is being presented and what is real; it is about accuracy, and is authenticity in the sense in which Salvati and Bullinger use the term. THE Phantom Pain (and perhaps all of the Metal Gear series) occupies an ambiguous position amongst military-themed action games, as its overarching narrative is inextricably linked to war, while also containing powerful anti-war messages. The authenticity of its representation of war is, as Salvati and Bullinger also acknowledge, related to discussions surrounding simulation, but also realism. Here, I am drawing on Alexander Galloway's seminal piece in discussing games as "realist" rather than 'realistic', focusing on social realism rather than photorealism (or even historical accuracy), achieved not only through visuals or narrative, but also action. ${ }^{44}$ Generally, scholars (including Galloway and Salvati and Bullinger) are at best ambivalent about the realism (or at times even potential realism) of war games, with most foregrounding war games' remediation of war films. As Campbell puts it, "authenticity connotes truth to the

\footnotetext{
42 Taylor, Yuval/ Barker, Hugh: Faking It: The Quest for Authenticity in Popular Music. London: Faber and Faber 2007, p. x.

${ }^{43}$ Ibid.

${ }^{44}$ Galloway, Alexander R.: "Social Realism in Gaming”, Game Studies 4 (2004).
} 
war film more than to what the war film represents." ${ }^{45}$ PHANTOM PAIN, however, lingers on the very aspects of war that are usually sanitized in traditional military shooters, despite its apparent cinematic nature. Repetition is central to gameplay, and not only emphasises the endless nature of a war in which rescuing child soldiers only means more child soldiers will take their place, but is also emblematic of the PTSD that is central to the game's narrative. The effects of war on those who fight it, as well as those places in which it is fought, are not sanitized but emphasized. As Girina argues, "The Phantom Pain foregrounds disparity and dramatizes sufferance, questioning the overall ideology of the conflicts that inhabit the game world." ${ }^{\prime 6}$ To call the game realist would, perhaps, be disingenuous, but its authenticity lies in its complex treatment of military conflict, and the player's role in it.

\section{Cultural Authenticity}

Cultural authenticity is defined as reflecting "a cultural tradition." 47 THE PhAnTom PAIN is significant in relation to both Japanese and American cultures, representing the transnational nature of digital games, but the culture that needs to be addressed here is gaming culture, where concepts of authenticity are both fraught and central. Consalvo and North examine the nature of 'authentic' or 'real' games in relation to ideas of legitimacy in gamer culture, outlining three types of criteria that constitute what is perceived to be a 'real' game, related to the game's pedigree, to the game itself, and to the payment structure of the game. ${ }^{48}$ Examining The PHANTOM PAIN against these criteria illustrates its position within gaming culture.

The payment structure criterion can easily be ticked here, as Consalvo and North primarily discuss the issues surrounding the authenticity of free-to-play games, whereas The Phantom Pain was released at \$59.99, a relatively common price point for AAA games at the time.

In terms of the game itself, Consalvo and North note three criteria that determine a game's realness: length, platform and control scheme, and social richness and perceived difficulty. HowLongToBeat.com places the running time of the game at a completionist running time of 163 hours, offering hardcore gamers a significant amount of main missions, side ops, and other management

\footnotetext{
45 Campbell, James: "Just Less than Total War: Simulating World War II as Ludic Nostalgia", In Zach Whalen/ Laurie N. Taylor (eds.) Playing with the Past: History and Nostalgia in Video Games, Nashville, TN: Vanderbilt University Press, p. 186.

${ }^{46}$ Girina, Ivan: "Needs to Be Done": The Representation of Torture in Video Games and in Metal Gear Solid V', in Berenike Jung/Stella Bruzzi (eds.) Beyond the Rhetoric of Pain. London: Routledge 2018, pp. 137-158.

${ }^{47}$ Y. Taylor/H. Barker: Faking It: The Quest for Authenticity in Popular Music, p. x.

${ }^{48}$ Consalvo, Mia/ Paul, Christopher A.: Real Games: What's Legitimate and What's Not in Contemporary Videogames. Cambridge, MA: MIT Press 2019.
} 
opportunities to venture in, although the need to replay missions at higher difficulty levels was criticised by some players. ${ }^{49}$ Like most AAA games, THE PhANTOM PAIN is available on PC as well as major consoles, thus avoiding the discussions of legitimacy that are often associated with mobile games. Consalvo and North focus on the "the "perceived' element" of "perceived difficulty" in that "the skill or skills to be showcased need to be considered and valued" and note that "focus here is placed on technical ability and the chance to show mastery." ${ }^{50}$ In The Phantom Pain, the game itself rewards mastery through its scoring system which ranks the quality of the player's performance, but also punishes the player if she pursues an easier difficulty through the Chicken Hat, which makes stealth easier, but forces the indignity of watching the player-character wear this absurd garment throughout the rest of the mission at hand, including during cut-scenes. Finally, the most important criterion for the current discussion is that of social richness, a key of which is "how they set up a framework - a gap - for things to be done outside them. Real games aren't just played on a platform; they are also a social platform through which to show skill, expertise, depth of knowledge, or offer a subject for extended discussion and analysis." ${ }^{51}$ Both the complex narrative of The Phantom PAIN and its numerous references to previous games in the series, clearly invite this type of discussion and necessitate in-depth knowledge of Kojima's work.

Lastly, the criterion which Consalvo and North emphasise the most is that of pedigree, whereby the legitimate status of a developer can outweigh many (if not all) of the other criteria. Both Konami and Kojima are names with decades of history within the games industry, and the METAL GEAR series itself has been part of that pedigree since 1987. The PhANTOM PAIN's status as culturally authentic is thus proven, and it is also linked to the final type of authenticity discussed here - personal authenticity.

\section{Personal Authenticity}

Personal authenticity "reflects the person or people who are making it." is related to auteur theory, and the perception of The Phantom PAin as the expression of Kojima's authorial intent. Here, affinities between auteur theory and the loaded discussion of authenticity throughout popular music, become evident, coalescing in the persona of the rock-star designer - Hideo Kojima. Like those musicians and filmmakers, Kojima is afforded what Moore describes as "first person authenticity", which arises "when an originator [...] succeeds in

\footnotetext{
${ }^{49} \mathrm{https}: / /$ howlongtobeat.com/game?id=5918

50 M. Consalvo/ C.A. Paul: Real Games: What's Legitimate and What's Not in Contemporary Videogames.

${ }^{51}$ Ibid.

${ }^{52}$ Y. Taylor/H. Barker: Faking It: The Quest for Authenticity in Popular Music, p. x.
} 
conveying the impression that his/her utterance is one of integrity, that it represents an attempt to communicate in an unmediated form with an audience." 53 Kojima's persona dominates the game, with his presence in THE Phantom PAIN emphasized through every credit sequence. ${ }^{54}$ The first moment of play illustrates this through a brief moment which occurs as the introduction to the first post-prologue mission, when Ocelot briefs player-character Snake as they ride through the desert. Before the player is allowed control, and as the cutscene ends, Ocelot's rousing speech concludes with the phrase: "Let the legend come back to life!" The camera pans to focus on Snake, and his horse neighs loudly, and rises on its hind legs, as the image freezes and the last line of the credits for the mission appears: "Created and Directed by Hideo Kojima." On a narrative level, the 'legend' may be Snake, and on the level of gameplay, the player may assume the role of the 'legend' as projective identity, but for that brief moment, the player is reminded that there is one 'legend' whose presence in the game cannot be questioned - that of Kojima himself. His vision, his personality, his style, are seen to be synonymous with the franchise, and inseparable from it, to such a degree that the series' post-Kojima game, METAL Gear Survive (2018) received an average user score of 1.4 according to Metacritic (despite more ambivalent critic reviews). ${ }^{55}$ Without its auteur, the series was itself considered to be inauthentic by a fandom unwilling to divorce it from its creator.

\section{Conclusions - Authenticity and the Mixtape}

In light of all that has been discussed, let us return to the game's opening scenes and opening song - Midge Ure's version of 'The Man Who Sold the World'. The song plays an important part in Green's extensive analysis of the opening scenes, where she refers to both the musical qualities of the song, describing it as "slower, hallucinatory, and much more dreamlike than the relatively up-tempo original," 56 but also to its lyrical content, which she sees as prefiguring the game's plot and its examination of identity and trauma. She argues that "the line, 'I never lost control,' repeated as part of the song's refrain, takes on more than one important meaning," focusing on both Snake's loss of control and the players' limited control in the tutorial sequences ${ }^{57}$ For Keerssemeeckers, the use of the song is what prompted his analysis, as "many people thought it was the

\footnotetext{
${ }^{53}$ Moore, Allan: “Authenticity as authentication”, In Popular Music, 21 (2002), p. 214.

${ }^{54}$ While credits usually appear at the beginning and end of a game, The Phantom Pain has credits at the beginning and end of each individual mission.

${ }_{55} \mathrm{https}$ ://www.metacritic.com/game/playstation-4/metal-gear-survive

${ }^{56}$ A. Green: Posttraumatic Stress Disorder, Trauma, and History in Metal Gear Solid V, p. 74 .

${ }^{57}$ Ibid.
} 
Bowie performance, which is apt, because of course Venom Snake secretly isn't Big Boss." 58 In other words, playing a cover song is seen as misleading the player, as the narrative of the game misleads her in its play with identities, only revealed at the game's true end. Moreover, Keerssemeeckers sees the song as being both about Snake, and about Kojima himself, who "can be thought of as the man who sold the world, ultimately abandoning his most famous creation and fans." 59 Building on this assertion, however, it can also be argued that the idea of control, so central to the lyrics of the song, is also central to the Konami-Kojima relationship, and the perception of the auteur as holder of artistic control.

To conclude, 'The Man Who Sold the World' exemplifies how the use of pre-existing music in THE PHANTOM PAIN simultaneously embodies ideas of authenticity in relation to the game and its narrative, its historical setting, and its auteur, but also subverts them. It is a cover version that plays with identities to begin with, obscuring the truth, but it also invariably evokes its original writer and performer, David Bowie, who himself challenged notions of authenticity in relation to rock music. The specters the song evokes and invokes are multiple, and bridge the real and the fictional throughout, as does the entire mixtape.

In other words, the appropriated popular music in the game distils all of the above forms of authenticity into one mixtape, as artefact and symbol, playlist and object. In terms of representation, it grounds the events of the game in a real historical past, but accuracy is clearly a secondary consideration. The interpretations of the mixtape in relation to both the broader plot of the game, and its creator, are part of the game's social richness and its status as 'real game', deserving of and requiring decryption and debate. Finally, the mixtape acts as a marker of personal authenticity, as autobiographical, as personal and public, as an unmitigated expression of the game's auteur. But, ultimately, the mixtape itself and its position are perhaps not as significant as the position from which it is analyzed.

Moore argues that "'authenticity' is a matter of interpretation which is made and fought for from within a cultural and, thus, historicized position. It is ascribed, not inscribed." 60 Ascribing different ideas of authenticity to THE PhANTOM PAIN is thus profoundly influenced by the historical context of both its production, and its reception. While videogames still struggle somewhat with their legitimacy within broader culture, and issues of legitimacy within videogame culture remain fraught with sexism and other forms of oppression and symbolic violence, the discussions of authenticity expressed here still marks a medium that has grown exponentially since the first Metal Gear game. The

\footnotetext{
${ }^{58}$ S. Keerssemeeckers, Stefan: "MGS 5's Soundtrack is All About the Kojima/Konami Split", 2017.

${ }^{59}$ Ibid.

${ }^{60}$ Moore, Allan: “Authenticity as authentication”, In Popular Music, 21 (2002), p. 210
} 
Phantom Pain`s 1984 setting also evokes a time when videogame designers were not yet sufficiently recognized or known by the public to raise discussions of auteurship, when videogames were not yet widely considered a medium appropriate for the discussion of serious topics such as PTSD, and a time when gamer culture was only just beginning to form. Kojima himself had not yet joined Konami, but was just discovering a medium that would become a form of authentic expression. Historicizing authenticity means acknowledging the positions from which discourses surrounding it are examined, how these have changed throughout the history of digital games, and how they are likely to evolve beyond contemporary considerations.

\section{BIBLIOGRAPHY}

Boym, Svetlana: The Future of Nostalgia. New York: Basic Books 2001.

Bull, Michael: Sounding out the City. Personal Stereos and the Management of Everyday Life. Oxford: Berg 2000.

Derrida, Jacques: Spectres of Marx, tr. Peggy Kamuf. Routledge: New York and London ([1993] 2006).

Campbell, James: "Just Less than Total War: Simulating World War II as Ludic Nostalgia", In Zach Whalen/ Laurie N. Taylor (eds.) Playing with the Past: History and Nostalgia in Video Games, Nashville, TN: Vanderbilt University Press, pp. 183-200.

Consalvo, Mia/ Paul, Christopher A.: Real Games: What's Legitimate and What's Not in Contemporary Videogames. Cambridge, MA: MIT Press 2019. Corrigan, Timothy: "Auteurs and the New Hollywood", In Jon Lewis (ed). The New American Cinema, Durham, NC: Duke University Press 1998, pp. 38-63.

Daughtry, J. Martin: "Aural Armor: Charting the militarization of the iPod in operation Iraqi freedom", In Sumanth Gopinath/ Jason Stanyek, (eds.). The Oxford Handbook of Mobile Music Studies, Volume 1, Oxford: Oxford University Press 2014, pp. 221-258.

DeNora, Tia: "Music as technology of the self", in: Poetics 27 (1999), pp. 31-35. du Gay, Paul/ Hall, Stuart/ Janes, Linda/ Mackay, Hugh/ Negus, Keith: Doing

Cultural Studies: The Story of the Sony Walkman, London: Sage Publications (in association with the Open University) [1997] 2013.

deWinter, Jennifer: "Miyamoto/Kojima: Authorship", In Matthew Thomas Payne/Nina B. Huntemann (eds.), How to Play Videogames. New York: New York University Press 2019, pp. 177-184.

deWinter, Jennifer: Shigeru Miyamoto: Super Mario Bros., Donkey Kong, The Legend of Zelda. New York: Bloomsbury 2015.

Eley, Craig: "Technostalgia and the Resurgence of Cassette Culture", In Joseph

P. Fisher/ Brian Flota (eds.) The Politics of Post-9/11 Music: Sound, Trauma, 
and the Music Industry in the Time of Terror, London: Ashgate 2011, pp. 43-54.

Galloway, Alexander R.: "Social Realism in Gaming", in: Game Studies 4 (2004).

Gibbons, William: "Wrap Your Troubles in Dreams: Popular Music, Narrative, and Dystopia in BioShock", in: Game Studies 11 (2011).

Girina, Ivan: "Needs to Be Done": The Representation of Torture in Video Games and in Metal Gear Solid V', in Berenike Jung/Stella Bruzzi (eds.) Beyond the Rhetoric of Pain. London: Routledge 2018, pp. 137-158.

Green, Amy: Posttraumatic Stress Disorder, Trauma, and History in Metal Gear

Solid V. London: Palgrave Macmillan 2017.

https://howlongtobeat.com/game?id=5918

Ivănescu, Andra: Appropriated Music in the Nostalgia Video Game: The Way It Never Sounded. Palgrave Macmillan: London 2019.

Keerssemeeckers, Stefan: "MGS 5's Soundtrack is All About the Kojima/Konami Split", in Kotaku, March 17, 2017, https://www.kotaku.co.uk/2017/03/17/mgs5s-soundtrack-is-all-about-the-koji ma-konami-split

https://www.metacritic.com/game/playstation-4/metal-gear-survive

Moore, Allan: "Authenticity as authentication", In Popular Music, 21 (2002), pp. 209-223.

Rando, David: Hope and Wish Image in Music Technology. London: Palgrave Macmillan 2017.

Salvati, Andrew/Bullinger, Jonathan M.: "Selective Authenticity and the Playable Past", In Matthew Wilhelm Kapell and Andrew B. R. Elliott (eds) Playing with the Past: Digital Games and the Simulation of History. New York, NY: Bloomsbury, pp. 153-167.

Sarris, Andrew: "Notes on Auteur Theory in 1962", In Leo Braudy/Marshall (eds.) Film Theory and Criticism, Oxford: Oxford University Press, pp. 561-565.

Tagg, Philip: Music's Meanings: A Modern Musicology for Non-Musos. New York \& Huddersfield: The Mass Media Music Scholars' Press 2012.

Taylor, Yuval/ Barker, Hugh: Faking It: The Quest for Authenticity in Popular Music. London: Faber and Faber 2007.

\section{LUDOGRAPHY}

BıSноск (2K Games 2007, O: 2K Boston/2K Australia)

Grand Theft Auto: Vice City (Rockstar Games 2002, O: Rockstar North)

Grand Theft Auto: San Andreas (Rockstar Games 2004, O: Rockstar North)

Gone Home (The Fullbright Company 2013, O: The Fullbright Company) 
Metal Gear Solid V: Ground Zeroes (Konami 2014, O: Kojima Productions)

Metal Gear Solid V: The Phantom Pain (Konami 2015, O: Kojima Productions)

Metal Gear Solid IV: Guns of the Patriots (Konami 2008, O: Kojima Productions)

Metal Gear Survive (Konami 2018, O: Konami Digital Entertainment)

\section{FILMOGRAPHY}

ApOCALYPSE Now (USA 1979, D: Francis Ford Coppola) 


\section{Authors}

Ivănescu, Andra, is a ludomusicologist and a lecturer in game studies at Brunel University London. Her research interests include genre, music for the moving image, and nostalgia. Andra has presented her research at national and international conferences, and has also published her work in journals including The Soundtrack and The Computer Games Journal. She is the author of Popular Music in the Nostalgia Video Game: The Way It Never Sounded, part of the Palgrave Studies in Audio-Visual Culture series. 